\title{
Down-regulation of CXCR7 inhibits the growth and lung metastasis of human hepatocellular carcinoma cells with highly metastatic potential
}

\author{
TONG-CHUN XUE ${ }^{1,2}$, RONG-XIN CHEN ${ }^{1,2}$, DAN HAN $^{1,2}$, JIE CHEN $^{1,2}$, QIONG XUE ${ }^{1,2}$, DONG-MEI GAO ${ }^{1,2}$, \\ RUI-XIA SUN ${ }^{1,2}$, ZHAO-YOU TANG ${ }^{1,2}$ and SHENG-LONG YE ${ }^{1,2}$ \\ ${ }^{1}$ Liver Cancer Institute, Zhongshan Hospital, Fudan University, Shanghai; ${ }^{2}$ Key Laboratory of Carcinogenesis \\ and Cancer Invasion (Fudan University), Ministry of Education, Shanghai, P.R. China
}

Received May 19, 2011; Accepted August 8, 2011

DOI: $10.3892 / \mathrm{etm} .2011 .358$

\begin{abstract}
CXCR7, a recently identified chemokine receptor, has been implicated in directing cancer metastasis. In the present study, the potential roles of CXCR7 in the growth and metastasis of hepatocellular carcinoma (HCC) were evaluated. A chemokine receptor gene chip was used to compare the expression of CXCR7 in HCC cell lines with different metastatic potential. Effects of targeting CXCR7 by RNA interference (RNAi) on the proliferation and metastasis of HCCLM3 cells were observed in vitro and in vivo. CXCR7 expression in 116 specimens from patients with or without metastatic HCC was assessed by tissue microarray. As a result, the gene chip showed that expression of CXCR7 was significantly higher in the highly metastatic HCCLM3 cells, which was confirmed by real-time RT-PCR and Western blotting. Chemotaxis assays showed that HCCLM3 cells responded to SDF- $1 \alpha$ from 1 to $100 \mu \mathrm{g} / 1$ and lung extractions $(1 \mathrm{~g} / \mathrm{l})$. Furthermore, down-regulation of CXCR7 in HCCLM3 cells by RNAi inhibited the proliferation and invasion of tumor cells in vitro. Moreover, CXCR7 knockdown significantly reduced the activity of matrix metalloproteinase- 2 and matrix metalloproteinase-9. RNAi of CXCR7 in the HCCLM3 cells also decreased the growth of tumors and the number of lung metastases in nude mice. The tissue microarray showed that HCCs with high expression of CXCR7 were prone to metastasize to the lung. These findings suggest that CXCR7 plays critical roles in the growth and metastasis of HCC. RNAi of CXCR7 inhibits the growth and invasion of tumor cells, which indicates that CXCR7 may be a potential molecular target for use in HCC therapy.
\end{abstract}

Correspondence to: Dr Sheng-Long Ye, Liver Cancer Institute, Zhongshan Hospital, Fudan University, 180 Fenglin Road, Shanghai 200032, P.R. China

E-mail: slye@shmu.edu.cn

Key words: chemokine receptor, CXCR7, metastasis, hepatocellular carcinoma, lung

\section{Introduction}

Hepatocellular carcinoma (HCC) is the most common form of primary liver cancer and the third most deadly malignancy worldwide, particularly in China where the mortality rate associated with $\mathrm{HCC}$ accounts for more than $50 \%$ of the worldwide rate (1). Metastasis is one of the main obtacles to improving the survival rate and long-term prognosis of patients with HCC. It is well known that the final site of metastasis of tumor cells is not random but organ-specific, in which chemokine receptors play important roles in the chemotaxis of tumor cells to target organs $(2,3)$. Identification of these metastasis-related chemokine receptors may provide potential targets for use in tumor therapy.

CXCR7, a recently identified orphan receptor, has been demonstrated to have the definitive ligand stromal cell-derived factor-1 (SDF-1) and truncated I-TAC (CXCL11) (4,5). CXCR7 has been found crucial for proper migration of primordial germ cells toward their targets in zebra fish (6). Recently, high expression of CXCR7 has been shown to be correlated with highly aggressive prostate tumors. (7) In addition, higher expression of CXCR7 was found to be linked to early and metastatic recurrence in pathological stage I non-small cell lung cancer (8). Most recently, research has reveaked the high expression of CXCR7 in the HCC cell line SMMC-7721 and overexpression in tumor tissues (9). However, whether CXCR7 participates in metastasis of HCC is yet unclear.

$\mathrm{HCC}$ is prone to metastasize to the lung, bone and brain; in particular lung metastasis occurs in $30 \%$ of patients with HCC. In the present study, expression of CXCR7 in HCC cell lines with different lung metastatic potential was observed. Furthermore, the effects of targeting CXCR7 on the proliferation and metastasis of a highly metastatic HCC cell line were observed in vitro and in vivo. Additionally, expression of CXCR7 in specimens from patients with metastatic HCC was evaluated.

\section{Materials and methods}

Cell lines. Three human HCC cell lines were used. HCCLM3 (100\% lung metastatic potential) and MHCC97-L (low metastatic potential) (10) were established in the Liver Cancer 
Table I. RNA interference strategy of CXCR7 in vivo.

\begin{tabular}{lcccc}
\hline Group & Pre-treatment & Drug & Dose & Application \\
\hline 1 & None & None & None & None \\
2 & siRNA-286 & None & None & None \\
3 & siRNA-286 & Chemically modified & $0.5 \mu \mathrm{g} / \mathrm{g}$ in $100 \mu \mathrm{l}$ & i.v., twice per week, continuous 7 weeks \\
& & siRNA-286 & & from inoculation, or days $1,4,8,11$, \\
& & & $15,18,22,25,29,32,36,39,43,46$ \\
\hline
\end{tabular}

Chemically modified siRNA can maintain stability at least one week in vivo. i.v., intravenous injection.

Institute of Fudan University. SMMC-7721 (without lung metastatic potential) was obtained from the Chinese Academy of Science (Shanghai, China). All cell lines were cultured in high glucose DMEM (Gibco-BRL, Grand Island, NY, USA) supplemented with $10 \%$ fetal bovine serum (Hyclone, UT, USA).

Animals. Male 6- to 8-week-old BALB/c nu/nu mice were obtained from the Chinese Academy of Sciences and maintained in accordance with the recommendations of the NIH Guidelines for the Care and Use of Laboratory Animals.

Patients. One hundred and sixteen specimens were used for the tissue microarray (TMA) preparation and consisted of paraffin tissue blocks from HCC patients. These patients underwent hepatic resection at the Liver Cancer Institute, Zhongshan Hospital of Fudan University from January 2000 to July 2004, and were followed up by pulmonary CT regularly until July 2009. All patients presented with pathological type HCC.

Gene microarray. Oligo GEArray ${ }^{\circledR}$ human chemokines and a chemokine receptor chip (SuperArray Bioscience, Frederick, MD, USA) was repeated twice to compare the profiles of the HCCLM3, MHCC97-L and SMMC-7721 cells. Total RNA was extracted, isolated and purified according to the protocol of the TRIzol reagent (Invitrogen Corp., Carlsbad, CA). Subsequent procedures were carried out according to protocols included in the SuperArray reagent packaging.

Real-time reverse transcription-PCR analyses. Real-time reverse transcription-PCR (RT-PCR) was carried out using TaqMan PCR reagents and the ABI PRISM 7700 sequence detection system (Applied Biosystems, Foster, CA) in accordance with a previously described protocol (11). Reactions were performed in $20-\mu 1$ volumes, each containing $2 \mu \mathrm{l}$ cDNA derived from $50 \mathrm{ng}$ RNA using the following primer pairs: CXCR7 sense, 5'-GGGATGCAGCGGATAGTCAA-3' and antisense, 5'-CGGTCGTTGTCCACATCCA-3'; Taqman probe, 5'-TCGGTCTCTCCCTGCCCGTCCT-3'.

Western blotting. Western blotting was performed according to the protocol of the Bio-Rad wet transfer using the Bio-Rad Transfer Cell system (Bio-Rad, Mississauga, Ontario, Canada). Rabbit anti-human CXCR7 IgG antibody (1:800, Novus Biologicals, Littleton, CO, USA) followed by 1:3,000 horseradish peroxidase-conjugated goat anti-rabbit $\operatorname{IgG} \mathrm{F}\left(\mathrm{ab}^{\prime}\right) 2$ antibody (Jackson ImmunoResearch, West Grove, PA) were used.
Chemotaxis assay and antibody inhibition assay. Lung extractions were prepared as described previously from nude mice (12). The chemotaxis assay was performed using a 24-well Transwell (Corning Costar Corporation, Corning, NY) in line with the protocol described by Hujanen and Terranova (13). In brief, the upper parts with polycarbonate filters $(8 \mu \mathrm{m}$ pore size) were coated with fibronectin $\left(5.0 \mu \mathrm{g} / 1 ; 37^{\circ} \mathrm{C}, 2 \mathrm{~h}\right)$. HCCLM3 cells $\left(1.0 \times 10^{3}\right.$ in $100 \mu$ l DMEM) were collected and added to the pre-coated wells. DMEM (600 $\mu \mathrm{l})$ containing SDF-1 $\alpha$ was added to the lower compartment. SDF-1 $\alpha$ (1 to $100 \mu \mathrm{g} / \mathrm{l})$ or lung extractions at $1 \mathrm{~g} / \mathrm{l}$ (12) were used. After $24 \mathrm{~h}$ at $37^{\circ} \mathrm{C}$, the cells migrating to the membrane were enumerated with Giemsa staining. Rabbit anti-human CXCR4 IgG antibody (Santa Cruz Biotechnology, Santa Cruz, CA, USA) at $20 \mu \mathrm{g} / \mathrm{ml}$ (14) was added when performing the inhibition assay. Each assay was performed three times independently.

RNA interference (RNAi). CXCR7 expression in HCCLM3 cells was down-regulated by small interference RNAs (siRNAs) which were designed and synthesized by GenePharma Corp. (Shanghai, China) as follows: siCXCR7-241, 5'-CGG UGA UGU GUC CCA ACA UdTdT-3' (position at 241 of CXCR7 mRNA); siCXCR7-286, 5'-CGC UCU CCU UCA UUU ACA UdTdT-3' (position at 286); siCXCR7-362, 5'-GGC CAA GAC CAC AGG CUA UdTdT-3' (position at 362); siCXCR7-1133, 5'-GGC CUU CAU CUU CAA GUA CdTdT-3' (position at 1133); negative control siRNA, 5'-UUC UCC GAA CGU GUC ACG UTT-3'; glyceraldehyde phosphate dehydrogenase (GAPDH) positive control siRNA, 5'-GUA UGA CAA CAG CCU CAA GTT-3'. SiRNA transfection of HCCLM3 cells was performed according to Lipofectamine 2000 protocol (15).

Cell proliferation assay. Cells $\left(3 \times 10^{3} /\right.$ well) were plated in 96-well plates $18 \mathrm{~h}$ prior to CXCR7 siRNA transfection. Transfection was carried out according to Lipofectamine 2000 96-well protocol. After incubation for 0-4 days, the cells were assayed for proliferation by the 3-(4,5-dimethylthiazol-2-yl)-2, 5-diphenyltetrazolium bromide assay (Chemicon, Temecula, CA, USA) following the manufacturer's protocol. Each assay was performed three times independently.

Invasion assay. In 24-well Transwell chambers, the upper parts with polycarbonate filters ( $8-\mu \mathrm{m}$ pore size; Costar, Acton, MA, USA) were coated with $50 \mu \mathrm{l}$ of Matrigel $\left(0.8 \mathrm{mg} / \mathrm{ml}, 37^{\circ} \mathrm{C}, 2 \mathrm{~h}\right)$ (BD Biosciences, San Diego, CA, USA). After siRNA transfection for $24 \mathrm{~h}$, HCCLM3 cells $\left(1.0 \times 10^{3}\right.$ in $100 \mu \mathrm{l}$ DMEM) 
were collected and added to the pre-coated wells. The cells were then allowed to migrate toward the lower compartment containing conditioned medium as a chemoattractant $\left(37^{\circ} \mathrm{C}\right.$, $40 \mathrm{~h}$ ). The cells migrating to the membrane were enumerated with Giemsa staining. The assay was performed three times independently.

Gelatin zymogram assay. HCCLM3 cells were transfected with siRNA of CXCR7 for 24 and $48 \mathrm{~h}$ prior to the gelatin zymogram assay. Analyses of matrix metalloproteinases (MMP)-2 and MMP-9 were performed on Novex zymogram gels (Invitrogen) as described by Jacob et al (16) except that $20 \mu \mathrm{g}$ supernatant/lane was run on a $10 \%$ Tris-glycine polyacrylamide gel containing $0.1 \%$ gelatin. Each assay was carried out thrice independently.

In vivo study. HCCLM3 tumors were established by subcutaneous injection of the tumor cells with or without CXCR7 siRNA transfection into the dorsal flanks of nude mice $\left(1 \times 10^{7} /\right.$ mouse, $\left.n=6\right)$. The RNAi strategy of CXCR7 in nude mice is described in Table I. On the 49th day after implantation, mice were sacrificed to examine tumor growth and metastases. Tumor size (tumor volume $=\mathrm{ab}^{2} / 2$ in $\mathrm{mm}^{3}$, where a and $b$ are the longest and the shortest perpendicular diameters of the tumor, respectively) and tumor weight were measured. Lung metastasis was evaluated using sequential sections of paraffin-embedded tissue.

TMA construction and immunohistochemical detection. Specimens from the HCC patients were divided into two groups: with or without lung metastasis. TMA was constructed in accordance with standard procedures as previously described $(17,18)$. Immunohistochemical detection of the TMA was carried out using the avidin-biotin complex method (ABC, Vector Laboratories, Burlingame, CA, USA). Rabbit anti-human CXCR7 IgG at 1:200 and rabbit anti-human CXCR4 IgG (Santa Cruz Biotechnology) at 1:100 were used as the primary antibodies for detection. Detection without a primary antibody was considered the negative control. The immunoassay was defined by the staining intensity (0-3) and the percentage of positive tumor cells as described previously (18). Two pathologists observed the results independently.

Statistical analysis. SPSS 15.0 Statistical Package (SPSS Inc., Chicago, IL, USA) was used to analyze the data. Results are expressed as the mean \pm SD. One-way ANOVA was used for intergroup comparisons. When two groups of cells or animals were compared, analysis was performed with the Student's t-test. Pearson Chi-square test or Fisher's exact test was used to compare qualitative variables. Differences between experimental results were considered to be significant at a $\mathrm{P}$-value $<0.05$.

\section{Results}

Expression of CXCR7 is significantly higher in a highly metastatic HCC cell line. The chemokine receptor gene chip showed that the expression of CXCR7, CXCR1 and CCR1 was up-regulated markedly in the highly metastatic HCCLM3 cells, particularly CXCR7 which demonstrated a significantly

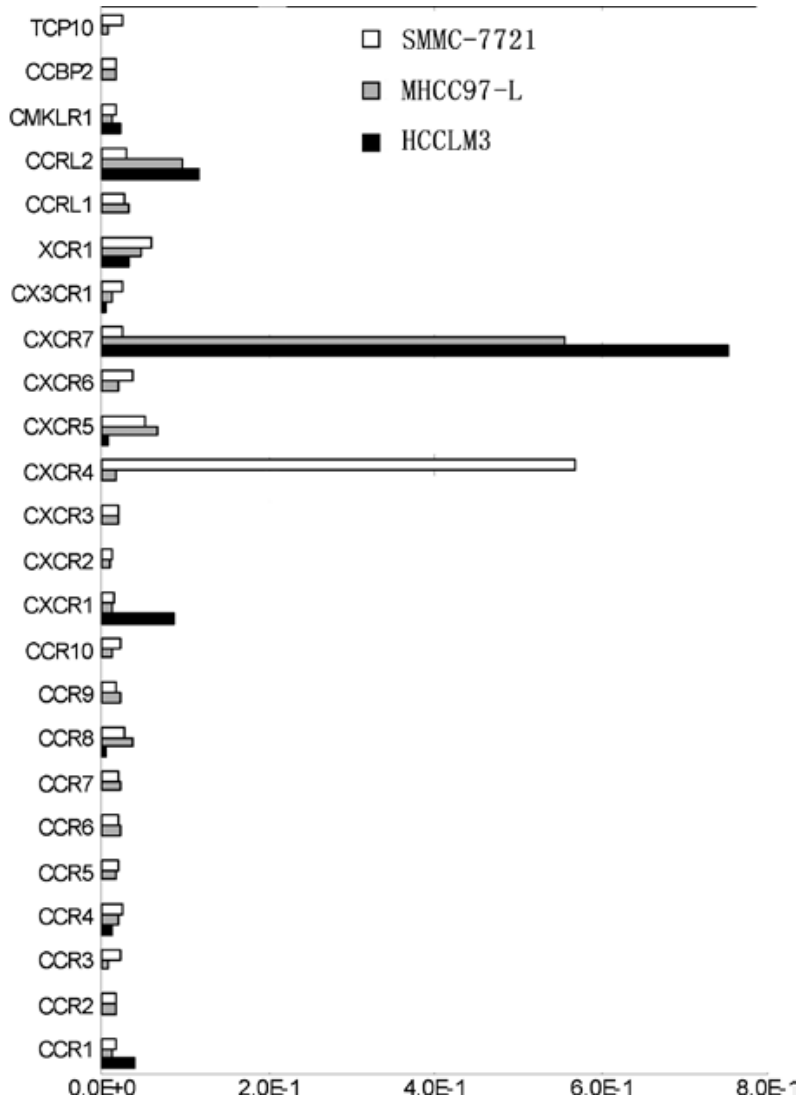

Figure 1. Chemokine receptor profiles of different metastatic HCC cell lines by microarray analysis.

high expression (Fig. 1). CXCR4, on the other hand, was nearly undetectable and CXCR7 exhibited a reverse trend of expression (Fig. 1). Furthermore, real-time PCR showed that the $\mathrm{Ct}$ value of CXCR7 relative to GAPDH was more markedly up-regulated in the HCCLM3 cell line than values in MHCC97-L and SMMC-7721 $\left(1.96 \pm 0.15 \times 10^{-3}\right.$ vs. $1.12 \pm 0.22 \times 10^{-3}$ and $0.13 \pm 0.10 \times 10^{-3}$, respectively; $\mathrm{P}<0.01$ ) (Fig. $2 \mathrm{~A}$ ). Western blotting showed that the protein level of CXCR7 was in accordance with the mRNA level $(\mathrm{P}<0.05)$ (Fig. 2B).

HCCLM3 cells functionally respond to SDF-1 $\alpha$ and lung extractions. Chemotaxis assay showed that the HCCLM3 cells responded to SDF-1 $\alpha$ from 1 to $100 \mathrm{ng} / \mathrm{ml}$, particularly at the concentration of $50 \mathrm{ng} / \mathrm{ml}(\mathrm{P}<0.01)$ (Fig. 2C). However, addition of the CXCR4 antibody $(20 \mu \mathrm{g} / \mathrm{ml})$ did not inhibit the response of HCCLM3 cells to SDF-1 $\alpha$ at the optimal concentration of $50 \mathrm{ng} / \mathrm{ml}(112 \pm 9 /$ field vs. $118 \pm 7 /$ field, $\mathrm{P}>0.05)$. Also, HCCLM3 cells were observed to respond better to lung extractions under $\mathrm{x} 400$ microscopy than MHCC97-L and DMEM ( $12 \pm 2 /$ field vs. $7 \pm 1 /$ field and $4 \pm 1 /$ field, respectively; $\mathrm{P}<0.05$ ). Addition of the CXCR4 antibody $(20 \mu \mathrm{g} / \mathrm{ml})$, however, did not inhibit the response of HCCLM3 cells to the lung extractions (12 $\pm 2 /$ field vs. $11 \pm 2 /$ field; P>0.05) (Fig. 2D).

RNAi down-regulates CXCR7 expression in HCCLM3 cells. To further study the function of CXCR7 in the growth and metastasis of HCC, gene silencing of CXCR7 in highly metastatic HCCLM3 cells was carried out by RNAi. Four pairs of siRNAs of CXCR7 were designed. Real-time PT-PCR and Western 
A

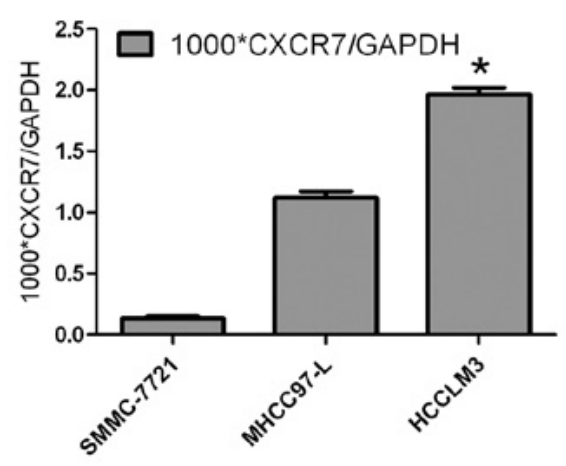

C

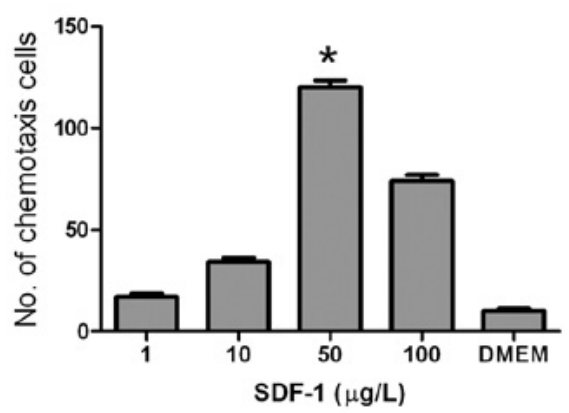

B

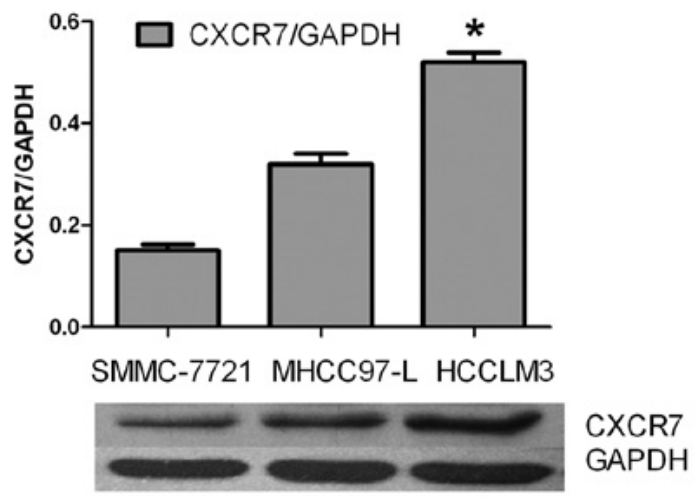

D

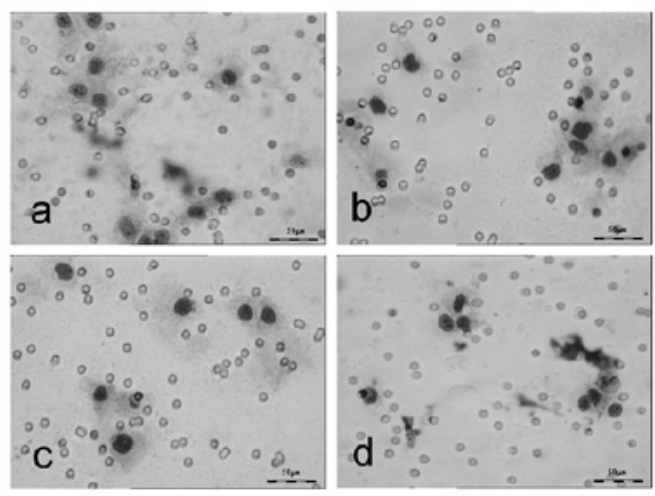

Figure 2. CXCR7 expression and chemotaxis assay. (A) mRNA transcript level of CXCR7 as determined by real-time RT-RCR ("P<0.01 vs. SMMC-7721 and MHCC97-L). (B) Protein expression of CXCR7 as examined by Western blotting ("P<0.01 vs. SMMC-7721 and MHCC97-L). (C) HCCLM3 cell response to SDF-1 from 1 to $100 \mathrm{ng} / \mathrm{ml}$, particularly at $50 \mathrm{ng} / \mathrm{ml}$ (ANOVA test, "P<0.01). (D) Lung extract ( $1 \mathrm{~g} / \mathrm{l}$ ) chemotaxis assay: (a) HCCLM3 response to lung extracts; (b) MHCC97-L response to lung extracts; (c) HCCLM3 response to DMEM control; (d) HCCLM3 response to lung extractions (1 g/l, $2 \mathrm{~h}$ ) after addition of the CXCR4 antibody $(20 \mu \mathrm{g} / \mathrm{ml})$. Giemsa staining of the cells on a Transwell membrane and observation at x400 magnification. Experiments were carried out thrice, with triplicate cultures each time. Columns, mean; bars, SD.

blotting demonstrated that siCXCR7-286 had the strongest inhibitory effect $(65 \%$ at $48 \mathrm{~h}$, mRNA level; and $72 \%$ at $72 \mathrm{~h}$, protein level, respectively). Therefore, siCXCR7-286 was used in the subsequent experiment.

Inhibition of the proliferation and metastatic potential of HCCLM3 cells by targeting CXCR7 in vitro. The cell proliferation assay revealed that the growth of the HCCLM3 cells was not obviously affected at 0,24 and $48 \mathrm{~h}$ after gene silencing of CXCR7 ( $>>0.05)$. However, cell growth decreased in the CXCR7 siRNA group compared to the siRNA control and liposome groups at 72 and $96 \mathrm{~h}$, respectively $(\mathrm{P}<0.01)$ (Fig. 3A). The invasion assay revealed that the HCCLM3 cells in the CXCR7 siRNA group exhibited a more significantly decreased invasive ability than those in the siRNA control and liposome groups (4.0 $\pm 1.0 /$ field vs. $8.3 \pm 1.5 /$ field and $10.3 \pm 1.5 /$ field, respectively; $\mathrm{P}<0.01$ ) (Fig. 3B). After RNA interference at 24 and $48 \mathrm{~h}$, the gelatin zymogram assay revealed a decreased expression of MMP2 and MMP9 in the CXCR7 siRNA group in comparison with that of the siRNA control and liposome groups $(\mathrm{P}<0.05)$, and down-regulation of MMP2 and MMP9 was stronger at $24 \mathrm{~h}$ than at $48 \mathrm{~h}$ after RNAi (Fig. 3C).

Gene silencing of CXCR7 inhibits the growth and lung metastasis of HCCLM3 tumors in vivo. Dissection of the subcutaneous tumors and evaluation of the lung metastases in mice were carried out on the 49th day. Results showed the complete formation of tumors in all mice (Fig. 3D). The volume and weight of tumors in the pre-interference group with and without regular intravenous injections were significantly smaller than those in the non-interference group (Table II). The group with pre-interference and regular intravenous injections showed slower tumor growth (volume and weight of tumors) than the pre-interference group without intravenous injections, which however had no significant difference $(\mathrm{P}>0.05)$ (Table II).

Lung metastasis was evaluated based on both the positive metastases in the lungs and the average number of metastases in the lungs per positive case. Sequential sections of the lung tissues showed that the metastatic nodules in the preinterference groups were significantly fewer than those in the non-interference group $(\mathrm{P}<0.01)$ (Table II). The number of cases presenting lung metastases in the group receiving preinterference and regular intravenous injections was less than that in the pre-interference group (3 of 6 vs. 4 of 6) (Table II).

CXCR7 is expressed highly in the tumor tissues of HCC patients with lung metastasis. TMA showed that the group with lung metastasis presented higher CXCR7 expression than the group without $(\mathrm{P}=0.017)$, and $\mathrm{CXCR} 7$ in tumor tissues was expressed much higher than that in the para-cancerous tissues $(\mathrm{P}=0.006)$ (Table III). In addition, CXCR4 expressin was shown to be lower in the tumor tissues than in the para-cancerous tissues 
Table II. CXCR7 siRNA treatment reduces HCCLM3 tumor size, weight and metastasis.

\begin{tabular}{lccccc}
\hline & \multicolumn{2}{c}{ Tumor size } & & \multicolumn{2}{c}{ Lung metastasis } \\
\cline { 2 - 3 } Treatment groups & Volume $\left(\mathrm{mm}^{3}\right)$ & Weight $(\mathrm{g})$ & & Cases $(\%)$ & Metastasis (no.) \\
\hline Non-interference & $1,265.42 \pm 900.01$ & $3.02 \pm 1.68$ & & 6 of $6(100)$ & $8.0 \pm 2.8$ \\
Pre-interference & $372.83 \pm 265.02^{\mathrm{a}}$ & $1.20 \pm 0.75^{\mathrm{a}}$ & & 4 of $6(66.7)$ & $2.5 \pm 2.0^{\mathrm{a}}$ \\
Pre-interferece and i.v. & $355.42 \pm 383.10^{\mathrm{b}}$ & $1.18 \pm 0.77^{\mathrm{b}}$ & & 3 of $6(50)$ & $2.3 \pm 2.2^{\mathrm{b}}$
\end{tabular}

${ }^{\mathrm{a}} \mathrm{P}<0.05$ vs. control group (non-interference); ${ }^{\mathrm{b}} \mathrm{P}<0.05$ vs. control group (non-interference). i.v., intravenous injection; no., number.

A

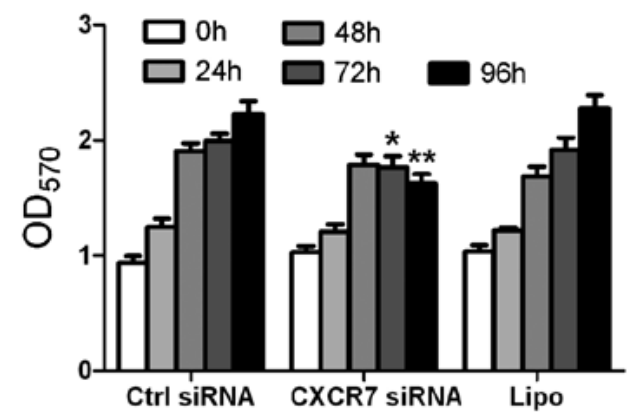

B
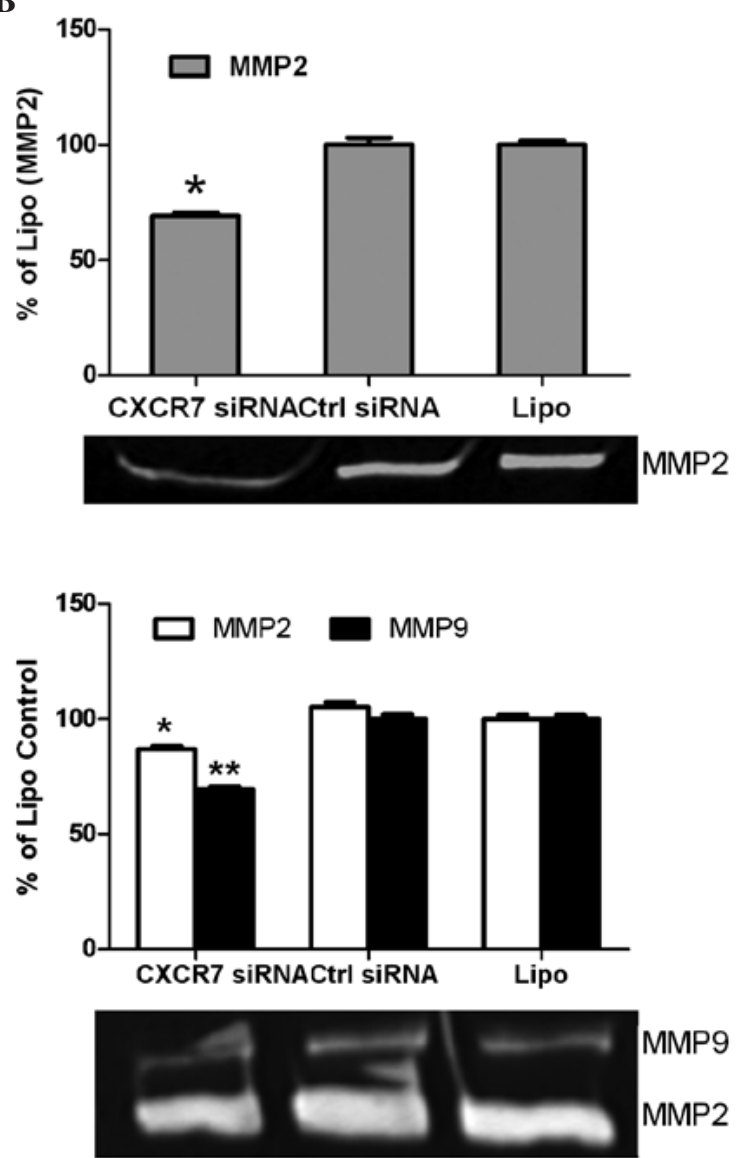

C

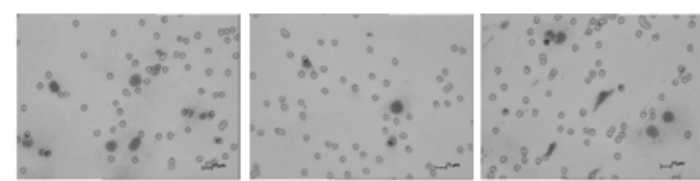

Ctrl siRNA CXCR7 siRNA Lipo

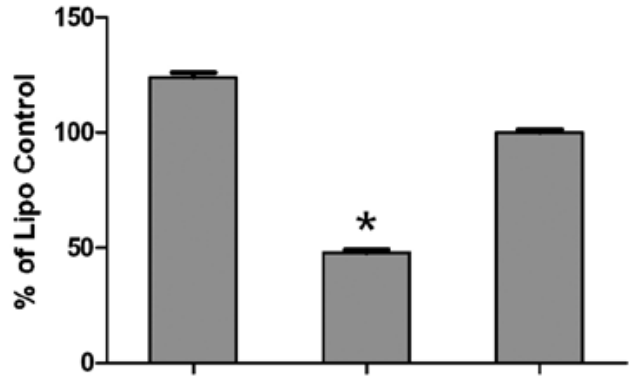

Ctrl siRNA CXCR7 siRNA Lipo

D

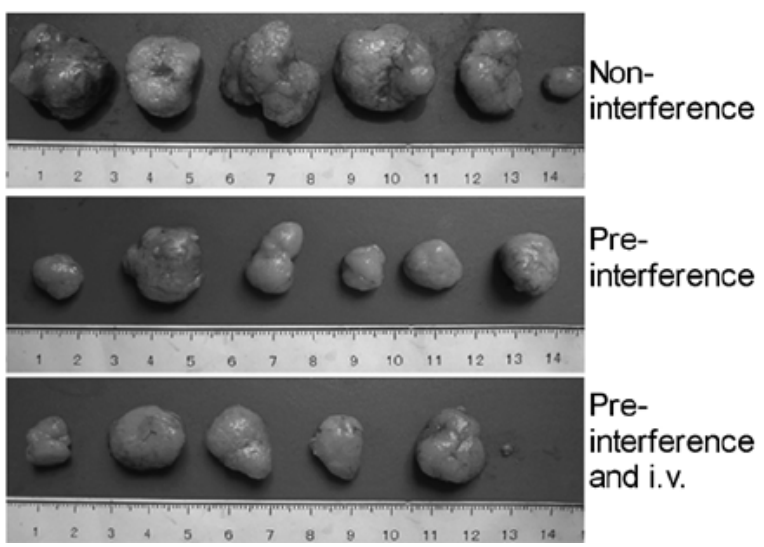

Figure 3. Inhibition of growth and metastasis of HCCLM3 cells in vitro and in vivo by targeting CXCR7. HCCLM3 cells were treated with CXCR7 siRNA, control siRNA (Ctrl siRNA), or Lipofectamine 2000 (Lipo). (A) Reduction of proliferation in HCCLM3 cells treated with CXCR7 siRNA at 72 and $96 \mathrm{~h}$ (B) MMP-2 and MMP-9 as determined by the gelatin zymography assay at $24 \mathrm{~h}$ (top) and $48 \mathrm{~h}$ (bottom) after treatment. (C) HCCLM3 cell migration in a Transwell invasion assay. Gemsa staining of tumor cells on a Transwell membrane (top) and quantitation of results (bottom). (D) Relative sizes of s.c. HCCLM3 tumors removed from nude mice ( $\mathrm{n}=6$ ) as indicated (day 49; in $\mathrm{cm}$ ). ${ }^{*} \mathrm{P}<0.01$ or ${ }^{* *} \mathrm{P}<0.01$ vs. group control siRNA and group Lipofectamine 2000. Experiments were carried out thrice. Columns, mean; bars, SD. 
Table III. Expression of CXCR7 and CXCR4 in the tissue microarray.

\begin{tabular}{|c|c|c|c|c|c|c|c|c|c|}
\hline & \multirow[b]{2}{*}{ No. of cases } & \multicolumn{3}{|c|}{ CXCR7 expression } & \multirow[b]{2}{*}{ P-value } & \multicolumn{3}{|c|}{ CXCR4 expression } & \multirow[b]{2}{*}{ P-value } \\
\hline & & $\begin{array}{c}\text { Weak } \\
+\end{array}$ & $\begin{array}{c}\text { Moderate } \\
++\end{array}$ & $\begin{array}{c}\text { Strong } \\
+++\end{array}$ & & $\begin{array}{c}\text { Weak } \\
+\end{array}$ & $\begin{array}{c}\text { Moderate } \\
++\end{array}$ & $\begin{array}{c}\text { Strong } \\
+++\end{array}$ & \\
\hline Tumor & 116 & 31 & 31 & 54 & $0.006^{\mathrm{a}}$ & 17 & 7 & 3 & \\
\hline Lung metastasis (yes) & 58 & 16 & 9 & 33 & $0.017^{\mathrm{b}}$ & 55 & 27 & 5 & $\mathrm{NS}^{\mathrm{b}}$ \\
\hline Lung metastasis (no) & 58 & 15 & 22 & 21 & & 44 & 24 & 15 & \\
\hline Adjacent-tumor & 47 & 6 & 30 & 11 & & 10 & 5 & 2 & $0.034^{\mathrm{a}}$ \\
\hline Lung metastasis (yes) & 23 & 3 & 12 & 8 & $\mathrm{NS}^{\mathrm{c}}$ & 28 & 11 & 6 & $\mathrm{NS}^{\mathrm{c}}$ \\
\hline Lung metastasis (no) & 24 & 3 & 18 & 3 & & 20 & 31 & 16 & \\
\hline
\end{tabular}

Lung metastasis (yes/no), with/without lung metastasis. ${ }^{\mathrm{a}} \mathrm{P}=0.006$ vs. adjacent-tumor and $\mathrm{P}=0.034$ vs. tumor; ${ }^{\mathrm{b}} \mathrm{P}=0.017 \mathrm{vs}$. lung metastasis (no); ${ }^{c}$ vs. lung metastasis (no). NS, not significant.

$(\mathrm{P}=0.034)$, and there was no significant difference between patients with and without lung metastasis $(\mathrm{P}>0.05)$ (Table III).

\section{Discussion}

In the present study, CXCR7 was demonstrated to play a critical role in metastatic HCC. First, we found increased expression of CXCR7 in a highly metastatic HCC cell line. Also, knockdown of CXCR7 in HCCLM3 inhibited the proliferation and invasion of tumor cells, as well as the decreased expression of MMP-2 and MMP-9. Furthermore, gene silencing of CXCR7 decreased the growth and lung metastasis of HCCLM3 tumors in nude mice. Finally, the TMA showed that CXCR7 was expressed higher in the tumor tissues of HCC patients with lung metastasis. Together, these findings suggest the potential roles of CXCR7 in both the growth and metastasis of HCC. Our finding that CXCR7 was associated with the growth and lung metastasis of HCC is partly in accordance with recently reported observations (9). In the present study, however, SMMC-7721 was used as a cell line with low metastatic potential due to its nearly non-metastatic ability to the lung. Expression of CXCR7 in SMMC-7721 cells was notably lower than that in HCCLM3 with highly metastatic potential in this study.

The chemokine receptor gene chip, in this study, showed marked up-regulated expression of CXCR7, CXCR1 and CCR1 and down-regulated expression of CXCR4. Our previous study showed that CCR1 is tightly related with local dissemination in the portal vein system (19). Downregulation of the expression of CCR1 by RNAi decreases the invasive and metastatic ability in vitro. Therefore, the chemokine receptor expression pattern observed in this study suggests that HCC, with high metastasis potential, exhibits a unique expression of chemokine receptors itself. Strongly up-regulated expression of CXCR7 and CCR1 may be a unique feature of metastatic HCC.

In the present study, CXCR7 expression was much stronger in the highly metastatic HCC cell line, whereas CXCR4 was not, which is partly in accordance with previous observation that CXCR4 expression is low in HCC cell lines with metastatic potential $(20,21)$. Schimanski et al (22) demonstrated a relationship between CXCR4 and lymphatic metastasis as well as dissemination. Recent research revealed that CXCR4 expression in HCC patients increases the risk of bone metastases and poor survival (23). SDF-1 $\alpha$ was also found to directly control the migration of both the leading and trailing edges of a tissue through the activation of two independent receptors, CXCR4b and CXCR7, in a zebrafish model, respectively (24). Since CXCR7 and CXCR4 share the same ligand or SDF-1, we believe that this unique expression style of CXCR7 and CXCR4 observed in our study suggests various potential unknown control mechanisms.

In this study, an in vitro cell culture demonstrated the growth inhibition of HCCLM3 cells by RNAi of CXCR7. Furthermore, the size of primary xenografted HCCLM3 tumors was markedly smaller in the pre-interference and pre-interference + i.v. groups in comparison with the noninterference group. This suggests that the pre-treatment of CXCR7 siRNA markedly reduces tumor growth in vitro and in vivo. Thus, tumor growth inhibition may be a major factor in the reduction of the number of metastatic lung tumors, which indicates that the anti-proliferative effect of the down-regulation of CXCR7 may be an important factor in the anti-metastasis mechanism. These findings are similar to observations in breast and lung models (25). In an osteoarthritis model (26), overexpressed CXCR7 in chondrocyte cells induced increased expression of osteopontin, interleukin-8, MMP2 and vascular endothelial growth factor, suggesting the potential roles of CXCR7 in the metastasis of HCC due to the close correlations between these genes and metastatic HCC. Recently, research has shown that ligand binding to CXCR7 does not result in the activation of signaling pathways typical of $\mathrm{G}$ proteins but does activate MAP kinases through $\beta$-arrestins, which suggests the role of CXCR7 in the non-classic pathway as a seven-transmembrane receptor (27). The mechanisms of CXCR7 participating in the growth and metastasis of HCC warrant further investigation.

In conclusion, the present study demonstrated the critical roles of CXCR7 in tumor growth and lung metastasis of HCC. RNAi of CXCR7 inhibited the growth and invasion of HCC cells, suggesting the potential therapeutic benefit of CXCR7 as a novel molecular target for HCC. 


\section{Acknowledgements}

This study was supported by a State Key Basic Research Program Grant from the Ministry of Science and Technology, China (no. 2004CB518708)

\section{References}

1. Parkin DM, Bray F, Ferlay $\mathbf{J}$ and Pisani P: Estimating the world cancer burden: Globocan 2000. Int J Cancer 94: 153-156, 2001.

2. Ben-Baruch A: Organ selectivity in metastasis: regulation by chemokines and their receptors. Clin Exp Metastasis 25: 345-356, 2008.

3. Kakinuma T and Hwang ST: Chemokines, chemokine receptors, and cancer metastasis. J Leukoc Biol 79: 639-651, 2006.

4. Balabanian K, Lagane B, Infantino S, et al: The chemokine SDF-1/CXCL12 binds to and signals through the orphan receptor RDC1 in T lymphocytes. J Biol Chem 280: 35760-35766, 2005.

5. Burns JM, Summers BC, Wang Y, et al: A novel chemokine receptor for SDF-1 and I-TAC involved in cell survival, cell adhesion, and tumor development. J Exp Med 203: 2201-2213, 2006.

6. Boldajipour B, Mahabaleshwar H, Kardash E, et al: Control of chemokine-guided cell migration by ligand sequestration. Cell 132: 463-473, 2008

7. Wang J, Shiozawa Y, Wang Y, et al: The role of CXCR7/RDC1 as a chemokine receptor for CXCL12/SDF-1 in prostate cancer. J Biol Chem 283: 4283-4294, 2008.

8. Iwakiri S, Mino N, Takahashi T, et al: Higher expression of chemokine receptor CXCR7 is linked to early and metastatic recurrence in pathological stage I non-small cell lung cancer. Cancer 115: 2580-2593, 2009.

9. Zheng K, Li HY, Su XL, et al: Chemokine receptor CXCR7 regulates the invasion, angiogenesis and tumor growth of human hepatocellular carcinoma cells. J Exp Clin Cancer Res 29: 31 , 2010.

10. Tian J, Tang ZY, Ye SL, et al: New human hepatocellular carcinoma (HCC) cell line with highly metastatic potential (MHCC97) and its expressions of the factors associated with metastasis. $\mathrm{Br} \mathbf{J}$ Cancer 81: 814-821, 1999.

11. Stordeur P, Poulin LF, Craciun L, et al: Cytokine mRNA quantification by real-time PCR. J Immunol Methods 259: 55-64, 2002.

12. Ji XN, Ye SL, Li Y, et al: Contributions of lung tissue extracts to invasion and migration of human hepatocellular carcinoma cells with various metastatic potentials. J Cancer Res Clin Oncol 129: $556-564,2003$
13. Hujanen ES and Terranova VP: Migration of tumor cells to organ-derived chemoattractants. Cancer Res 45: 3517-3521, 1985.

14. Muller A, Homey B, Soto H, et al: Involvement of chemokine receptors in breast cancer metastasis. Nature 410: 50-56, 2001.

15. Dalby B, Cates S, Harris A, et al: Advanced transfection with Lipofectamine 2000 reagent: primary neurons, siRNA, and highthroughput applications. Methods 33: 95-103, 2004.

16. Jacob K, Webber M, Benayahu D and Kleinman HK: Osteonectin promotes prostate cancer cell migration and invasion: a possible mechanism for metastasis to bone. Cancer Res 59: 4453-4457, 1999.

17. Simon R, Mirlacher M and Sauter G: Tissue microarrays. Methods Mol Med 97: 377-389, 2004.

18. Lugli A, Spichtin H, Maurer R, et al: EphB2 expression across 138 human tumor types in a tissue microarray: high levels of expression in gastrointestinal cancers. Clin Cancer Res 11: 6450-6458, 2005.

19. Wu X, Fan J, Wang X, et al: Downregulation of CCR1 inhibits human hepatocellular carcinoma cell invasion. Biochem Biophys Res Commun 355: 866-871, 2007.

20. Begum NA, Shibuta K, Mori M and Barnard GF: Reduced expression of the CXCR4 receptor mRNA in hepatocellular carcinoma and lack of inducibility of its ligand $\alpha$-chemokine hIRH/SDF1 $\alpha /$ PBSF in vitro. Int J Oncol 14: 927-934, 1999.

21. Mitra P, De A, Ethier MF, et al: Loss of chemokine SDF-1alphamediated CXCR4 signalling and receptor internalization in human hepatoma cell line HepG2. Cell Signal 13: 311-319, 2001.

22. Schimanski CC, Bahre R, Gockel I, et al: Dissemination of hepatocellular carcinoma is mediated via chemokine receptor CXCR4. Br J Cancer 95: 210-217, 2006.

23. Xiang ZL, Zeng ZC, Tang ZY, et al: Chemokine receptor CXCR4 expression in hepatocellular carcinoma patients increases the risk of bone metastases and poor survival. BMC Cancer 9: 176, 2009.

24. Valentin G, Haas P and Gilmour D: The chemokine SDF1a coordinates tissue migration through the spatially restricted activation of Cxcr7 and Cxcr4b. Curr Biol 17: 1026-1031, 2007.

25. Miao Z, Luker KE, Summers BC, et al: CXCR7 (RDC1) promotes breast and lung tumor growth in vivo and is expressed on tumor-associated vasculature. Proc Natl Acad Sci USA 104 15735-15740, 2007.

26. Jones SW, Brockbank SM, Mobbs ML, et al: The orphan G-protein coupled receptor RDC1: evidence for a role in chondrocyte hypertrophy and articular cartilage matrix turnover. Osteoarthritis Cartilage 14: 597-608, 2006.

27. Rajagopal S, Kim J, Ahn S, et al: Beta-arrestin - but not G proteinmediated signaling by the 'decoy' receptor CXCR7. Proc Natl Acad Sci USA 107: 628-632, 2010. 